\title{
Escritos de artista
}

\section{Nuno Ramos}



A pedido dos editores de Ars, escolhi para a revista alguns textos de Nuno Ramos extraídos de seus livros, abarcando um largo período de tempo, do primeiro publicado, Cujo (1993), a um dos mais recentes, Sermões (2015). Deixei de fora aqueles decididamente ensaísticos. De qualquer modo, é difícil, e a essa altura ocioso, resolver o que são os textos de Nuno, sempre se ramificando por entre a poesia (inclusive a de canção), a narrativa de ficção (em si mesma uma noção instável que dança com a de verdade) e o ensaio (a mais tentativa das definições da prosa pensante). E tudo se mistura ainda mais por conta da convivência com a sua produção como artista, em que a linguagem entra e vaza por todos os lados. Paralelamente, seus textos estão cheios de referências materiais em escala vertiginosa, dos fluidos do corpo às manifestações telúricas, com uma estranha habilidade de se embrenhar em palavras e coisas, de toscos acontecimentos a maravilhas aflitivas (mas também o contrário). O fato é que, antes ainda de publicar livros, ele começou trabalhando com a imaginação da escrita e, a certa altura dos anos 1980, passou a se estender - e quanto, desde então - também pelo universo material da arte. Arte plástica, arte visual, arte contemporânea - sempre o problema da proliferação e simultânea insuficiência dos nomes. Certamente um de seus problemas como escritor e/ou artista. E aqui, como alhures, nosso também

João Bandeira 
Comecei a arrancar a pele das coisas. Queria ver o que havia debaixo. Ergui a superfície do assoalho, que saiu inteira, sem quebrar. Tive de descascar a pele dos tijolos aos poucos, com paciência. A pele do cimento era a mais fina de todas e a dos azulejos refletia como um espelho. Debaixo destas peles parecia haver outra pele, idêntica porém enrugada. Retirei mais esta camada e o enrugado da superfície aumentou. Fui retirando camadas sucessivas, cada vez mais onduladas e acidentadas. A pele da tábua do assoalho foi a primeira a apresentar grandes rombos e uma tonalidade avermelhada apareceu em sua parte inferior. Pequenas farpas de madeira prendiam-se agora a ela, perfurando-a em diversos pontos. As camadas da pele do cimento começaram a grudar umas nas outras. Já não era possível retirá-las tão finas (quase transparentes) e a força empregada passou a ser bem maior (tinha os braços cansados, agora). A alteração mais triste acompanhou a pele dos azulejos: quanto mais profundas, mais opacas ficavam as camadas. A nitidez especular da primeira pele (bem superior à do azulejo inteiro) transformou-se pouco a pouco na tonalidade leitosa de um dia nebuloso ou de um olho vazado. A pele dos tijolos foi simplesmente virando pó: se no início era ainda possível descascá-la, havia perdido agora toda consistência e se desintegrava ao primeiro toque. Não era mais uma pele, nem uma superfície: transformara-se num material arenoso qualquer. Podia ser pó de tijolo, cal, areia ou, quem sabe, os restos de um defunto. Por trás de cada pele, portanto, encontrei apenas forma degradadas da pele superficial. Ainda que os dados não sejam suficientes, devo concluir que esta primeira camada não recobre um interior diferenciado, mas é a expressão mais estável deste interior, que a repete monotonamente ${ }^{1}$.
Nuno Ramos

Escritos de artista

1. RAMOS, Nuno. Cujo. Rio de Janeiro: Ed. 34, 1993, p. 29-31. 
ARS Duas formas de instabilidade: brilho (multiplicação de uma superfície) ano 15 e umidade (degradação ou evolução da superfície original numa outra). n. 31 A escultura ganhará presença através destes dois modos, ou seja: através de sua possibilidade de degradação ou evolução e de sua capacidade de refletir, de receber a aparência de uma outra superfície. Além disto, no limite, a escultura deve durar um instante. Se dura para sempre, não 2. Ibidem, p. 33. dura para ninguém ${ }^{2}$. 
Devolver a cada pele as outras que perdeu, a fumaça à agua, à gasolina, ao vidro. A pele da zebra deve encrespar-se, áspera como o couro do tatu ou frágil como uma folha seca e quebradiça. A troca constante entre as qualidades das peles devolveria ao mundo sua potencialidade original: a de tudo tornar-se a aparência de tudo, sem privilegiar nenhum momento específico. Seria preciso que o centímetro se assemelhasse ao quilômetro, o um ao vário, o dia à noite etc. Todas as medidas quantitativas, devido à sucessão inesgotável de possibilidades, ficariam reduzidas a uma única medida. $\mathrm{O}$ mesmo com as cores, as palavras, as notas musicais. $\mathrm{O}$ azul-turquesa, por exemplo, seria o invólucro dos tons e semitons infinitos, atualizados naquele azul (incluindo aí o próprio azul-turquesa). A palavra portuguesa cedro seria o sinal vazio de todas as outras palavras em todas as outras línguas (incluindo aí a própria palavra cedro). O si bemol seria o som suspenso onde penetrariam sem cessar todos os outros sons (incluindo aí o próprio si bemol). Assim o todo se faria o tempo todo, numa monotonia variada, sem dar tempo ou nome aos seus pedaços ${ }^{3}$.
Nuno Ramos

Escritos de artista

3. Ibidem, p. 67. 


\section{ARS Tró-ló-ló}

Ali. Encontrei jogada. Peso, puxe. Para baixo, para baixo. Ao meu comando. Assim: passo, ande. Caia, tendendo para o chão, para a poça. Mas digo. Aceito. Cem vezes repito: no centro disso tudo há uma. Sabia? Ouviu? Ali. De novo. Bem baixinho. Ela. Agora. Can-ção. Ou-ça. Gi-gi-gi-gi-gante. Pé dentro, pé fora. Ouviu? Sussuro. De novo: canção. $\mathrm{O}$ cravo brigou com a rosa. Eu mando. O mar quando quebra na praia. É bonito. Mando agora. Dou ordens. Peitos, caiam. Cabelos, cresçam. Mas mesmo aí, no centro da gra-gra-gravidade eu descobri uma canção. Tendendo para o centro, atraída irresistivelmente para o centro, derrubando maçãs. A Física inteira é um pequeno acorde passageiro seu. O próprio dinheiro e a circulação do capital são apenas o pedaço de uma sílaba da segunda parte. Ventos, velames, sal nos pulmões. Náufragos amarrados a seus naufrágios; desastres untados aos desastrados. Tró-ló-ló. Gesto do polegar em círculos sobre a orelha. Psss. Acorde. Acorde para abrir os olhos para: vê a minha mão?Montanha, aponta. Suas linhas, adivinha? - cançoneta. Sambinha. Juro. Eu é que sei. Pr-pr-pr-pró-pró-pró-próprio da minha pessoa. Eu descobri. Agora, um apito. Vai. A soma dos suspiros. Os ais de amor. Chama. Nome. Geme. Ouviu? Mais. Eu sei, no centro do pulmão da árvore há um mel viscoso. Eu sei, no centro do mel da chuva, no anel central, cervical, da coluna imensa que sustenta tudo, a polpa amarga contaminada, noturna, escapa, feita de grãos minúsculos. Entre eles há imensos campos abertos, de cana, soja, trigais. Estes campos são feitos de música. Música, pss. Ouça. Tr-tr-tr-tró-tró-tró-ló-ló. Mas não basta isso. Soprar a flauta não basta. Agitar a batuta com a cara pomposa, depois curvar-se ante os aplausos, depois celebrar com espuma no copo de cristal, não: antes disso, na própria composição uma canção domina, cançoneta. Ei-la. Lua líquida. Cosmo de papel. O peso fantasiado, a curvatura do espaço transformada, os pés chumbados ao chão, diga: bemol. Vê? Suspensão anterior à dominante. Escala menor. Assim, como uma progressão, bem no centro do que se apresenta. Em camisa de força, ouça: no centro, vou dizer: da Li-te-ra-tu-ra e também, coragem, prossiga, vou dizer claramente, do Ci-ne-ma e ainda, agora vou até o fim, da Escul-tu-ra e da própria Cla-ri-da-de há o quê, já falei, uma canção, uma canção que não compus, mas colhi. Estava ali me esperando, jogada. $\mathrm{Na}$ sarjeta, sim, escapando depois que a traguei, uff, aspira, puff, por todos os meus órgãos, contaminando com bacilos de última geração minha sombra e minha respiração, e ainda o teor de açúcar em meu sangue e a curva exata da minha coluna, a gordura em meu fígado e a coloração 
dos meus cabelos. Eu me lancei então, os bolsos cheios dessa, ouça: vê?, põe a mão aqui, ó, no meu, claro, desculpe, uma ereção, cuspe, vê: aqui carrego, nesse músculo concentro, nessa ideia represento, nesses braços levanto a própria, ela mesma, a música anunciada, o hino secreto do esqueleto sexual que ergue as árvores e a solidez do caroço e do mármore, a canção a que me refiro desde o início, atirada aos meus pés como um bebê abandonado ${ }^{4}$.
Nuno Ramos

Escritos de artista

4. Idem. 0 mau vidraceiro. São Paulo: Globo, 2010, p. 65-67. 


\section{ARS Bonecos trocados}

ano 15

n. 31 Inflei os bonecos de notícia, mas a voz era da boneca do tempo. Então, com uma agulha, furei os dois bonecos de notícia, que saíram flutuando pelo quarto. Rapidamente, inflei o boneco de esportes, mas a voz era dos bonecos de notícia. Cansado daquilo, inflei o boneco que comentava política e ouvi a noite toda sua voz calma e irônica detalhando os últimos acontecimentos na Câmara dos Deputados. No dia seguinte, liguei para o técnico, que veio consertar meus bonecos. Ao ver os dois bonecos de notícia furados no chão, um sobre o outro, olhou espantado para mim. Por que fez isso?, perguntou. Por raiva. A voz estava trocada, eles só anunciavam frentes frias. Então, com uma voz sutil me perguntou, Você conhece a minha moça do tempo?, e por um dinheirinho extra me forneceu uma boneca que, ao invés da previsão do tempo, só diz impropérios 5 . 


\section{Regras para a direção do corpo}

\section{Introdução}

Há um corpo.

As asas. Os tufos. As fontes. Os sebos. Os cuspes. As porras. As pupilas límpidas, azuis ou verdes. Onde bate o pôr do sol laranja. Os órgãos. Os nacos sangrentos. Os filtros. A borra esverdeada do que não pôde ser expelido. Mas que foi, no entanto, expelido. $\mathrm{O}$ anonimato de cada rosto interno, já que todos os órgãos parecem iguais (examinaremos isso mais adiante). Um estômago parece igual a outro. Nunca se ouviu de um cirurgião, ao abrir um paciente, a exclamação - que rim lindo! Que rim perfeito! E por quê? E por que não?

Isto tudo está vocacionado para funcionar - não como uma máquina, mas como uma multidão entusiasmada, tomada por um princípio único, marujos dirigidos por um capitão benquisto, soldados hasteando uma bandeira enorme, criancinhas de colégio na saída para o pátio. Assim é a saúde: entusiasmo.

Há um bicho.

Há a foice.

E há os pés.

Há as horas, há duas horas. Há minutos. Há poeira, sal.

Há a perda da gordura, a queima direta da proteína.

Há a próstata.

Há a decisão, quanto ao membro amputado, de considerá-lo alguém, um ser autônomo, dando-lhe sepultamento. Mas seria preciso, para isto, inscrever na lápide, além das duas datas, de nascimento e morte, um nome próprio que o identificasse. Que nome dar a um rim? Como batizar uma perna, um seio, um dente do siso, um tufo de pelos? O amplexo, o abraço, o toque, o beijo de língua e a pele tatuada podem construir uma espécie de corpo coletivo, projetado sobre os mais distintos corpos vivos ou superfícies mortas. Assim, a aparência de um 

nesse besouro. Há, sim.

Os ossos lá dentro, esperando, quietos.

\section{Modo de usar}

\section{a) As regras que o corpo emite são cegas}

O corpo acontece. Manda e obedece. Chora e é chorado. Estamos falando de controle. Durma, e por mais cinzento que seja o sonho, ronque muito. Coma, e por mais amarga a fruta, morda muito, e babe o sumo. E diga, ó manhã azul de um dia extenso, a todos os dias que nascerem azuis. E cante. Cante como um inseto deve morder, saciado do sangue alheio.

\section{b) As regras que o corpo emite são mudas}

Estamos, portanto, falando de música. Os cabelos é que as transmitem, pela capilaridade gordurosa próxima às áreas irrigadas. Claro que não estão ali apenas para proteger a cabeça, o sexo e as axilas do frio. Estão ali para transmitir as ordens. Ordens de quem? Para quem?

\section{c) Não há propriamente comando nestas regras}

Comando no sentido de um agente claro ou de uma central de ordens há um consenso aparente, voluntário e quase unânime (ainda aqui, o entusiasmo conduz toda a operação). Este consenso, no entanto, exclui muita coisa - há desarme e contenção periféricos e todo corpo é um corpo invadido e contrariado, mesmo em pleno gozo. As partes que não se submeteram são violentamente silenciadas pela maioria consensual que soletra, baixinho, fodam-se os descontentes, num coro quase marcial. Ainda aqui, é o entusiasmo que permite o funcionamento do organismo, tomado em sua totalidade.

\section{d) As partes submetidas às regras transformam-se imediatamente em opressoras daquelas que ainda não foram conquistadas, gerando mais e mais consenso}

Este é o segredo do corpo saudável: a troca entre o que é neutro e o que é ativo, entre o general e o soldado, entre a bomba e o bombardeado, a conversão contínua e desimpedida de um extremo no outro.

e) 0 corpo parece, assim, espontâneo quando é astucioso e indiviso quando é profundamente dividido 


\section{Regras para a direção do corpo}

Regra I

Ande sempre em linha reta.

\section{Regra II}

Ouça os idiotas, ouça os distraídos.

\section{Regra III}

Toque o pelo das taturanas, ainda que arda. Tudo te é contíguo porque você é extenso. Os idiotas também são extensos, e tão cheios de peso quanto você. $\mathrm{E}$ os cretinos. $\mathrm{E}$ os distraídos. $\mathrm{E}$ aqueles que mancam. E os ruivos.

\section{Regra IV}

Pise com propriedade. Há um modo de pisar a pedra, como há um modo de pisar a poça, como há um modo de pisar um rosto, como há um modo de pisar um raio. Há um modo de pisar um pão. Há vários pés, inúmeras solas. Aprenda cada um deles. Depois, e isto é bem mais complicado, fabrique teu próprio sapato. Sapato e óculo (ver Regra $x$ ) são os únicos artefatos de que trataremos aqui. Lembre que, se não puder andar, não pode mais nada. E quanto mais velho for, de mais sapatos precisará. Há os pés.

\section{Regra $v$}

Não há estrelas, não olhe para cima. Não é por ser curioso que deve olhar embaixo das coisas ou dentro de valises e gavetas. Nenhuma saudade te fará olhar sobre os ombros, furtivo; nenhuma confiança tornará teu olhar altivo, fixo à frente. Não fite tuas mãos, como quem cometeu um crime. Nem os pés, como quem recebe um pito. Nunca olhe um muro fixamente, como quem pensa. Nem arregale os olhos, como quem se espanta ou viu um fantasma. Não exclame é bonito! diante da paisagem, nem ria do que fazem à sua frente. Contenha teus olhos. Não fite jamais um cadáver.

\section{Regra VI}

Quando você se debruçar, prepare-se para o salto. Quando prender em tua mão, prepare-se para a posse. E quando socar, destrua de vez. Vá até o fim do corpo alheio, tirando dele o teu proveito. Morda a folha, arranque o caule, cave a terra, aprisione a luz em teu espelho, até que solte sua resina. Não recue nunca, por medo do corpo de um outro. Se 
te tocarem, toque de volta. Encontre a região secreta, a lembrança frágil nho, como um boneco de piche grudento. Nada tema no corpo alheio mesmo o pior dos elementos (o fogo) pode aquecer docemente. Num incêndio, proteja primeiro os cabelos.

\section{Regra VII}

Tua voz é teu corpo ainda, bem como as lágrimas e teu suor (até evaporarem), tua porra (até secar). Quando der um grito, lembre que teu pâncreas também grita, e destila gritando a sua resina verde. Isso é evidente na dor - o corpo inteiro sofre - e nas convulsões do prazer - o corpo inteiro goza - mas, é preciso lembrar, nos pequenos atos há a mesma passagem entre a parte e o todo. O fígado também anda, o rim se deita, o olho canta e a voz caga.

\section{Regra VIII}

Tua mão não é tua mão, mas o que você sabe e domina da tua mão. Assim, entre o que para você funciona e o que tem disponível nessa mão, mas não usa, há um grande hiato. Mas lembre: outras épocas, outras culturas, usaram outros gestos e não ligaram para os gestos que você emprega, selecionando outros itens do menu-mão. $\mathrm{O}$ mesmo para o que vê, o mesmo para o que canta. No entanto, os gestos que você nunca fez, as notas que nunca cantou, também vivem, e passam, dentro de você, o tempo de vida que te será dado. Eles também são órgão há, em teu rim, uma acidez que ele nunca filtrou, aguardando —, eles também são corpo. Preste atenção.

\section{Regra IX}

Aceite a ilusão-manhã pela manhã, a ilusão da noite quando for noite. Aceite a ilusão da chuva quando chover. Por manhã quero dizer: fôlego, como se você respirasse o plástico, a casca das árvores, a tinta dos jornais diários. Por noite quero dizer: tato, como se você tocasse um muro de pele humana, pisasse num asfalto felpudo de camurça escura. Por chuva quero dizer: banho, como se quando você se lavasse, deixasse para trás o que te prende - memória, poeira, sofrimento e perda.

\section{Regra $X$}

Se precisar, sim, use óculos. Vidros curvos conservam o alcance da visão, o contorno dos detalhes, a nitidez num fundo de cena. Mas nunca, em hipótese alguma, use óculos escuros. A luz não pode ser combatida. 
Investigadores policiais, que querem ver sem ser vistos, atores famosos,

te anódina, aceitando sua lassidão cinzenta e perene, como se tivessem as pontas dos dedos anestesiadas ou o palato coberto por uma camada de poeira. As janelas de vidro escuro também devem ser evitadas.

\section{Regra XI}

Aceite a cirurgia.

\section{Regra XII}

Trate teu sexo como um braço ou joelho, e teu joelho como se fosse sexo. Há agora, com o desenvolvimento de novas técnicas microcirúrgicas, a possibilidade de implantação de pequenas vulvas em cartilagens em meio ao ligamento cruzado do joelho, por exemplo, ou na extremidade do nariz. Aceite a cirurgia (Regra XI). A verdadeira questão, no entanto, não está na sexualização do corpo, mas na corporificação do sexo. Apanhe teu pau - é um troço, um tanto de quilo de carne inchada pousado em tua mão. Afunde o dedo em tua vulva: mexilhões, uvas apodrecendo. Teu sexo se espalha na matéria, num estado da matéria, difuso e constante. Procure por ele.

\section{Regra XIII}

Ande sempre em linha reta (Regra I), mas procure a curva quando dançar. Então abra os braços, busque a espinha ereta e o contrapeso de um pé para trás. Se for cair, caia enrodilhado.

\section{Regra XIV}

Não deixe que te expliquem como teu corpo funciona. O enigma do relógio não está na composição de suas partes, mas na duração de sua corda.

\section{Regra XV}

Autorretrato - Comece, como os pintores, pelo rosto, mas espalhe, aos poucos, o rosto pelo corpo inteiro - cabelo é rosto, omoplata, curva dos quadris, orifícios, tudo é rosto. Depois, tome um chão de folhas secas por teu rosto. E a pupila de um cão que ladra. E a madeira transformada (mesa, tablado), e o estampido ecoando pela sala.

\section{Regra XVI}

Aqui não há pés, mas pise. Não há olhos, mas chore. Aqui não há cabelos, mas trance e penteie, espalhando os fios que caírem. Aqui não 
ARS há pâncreas, mas filtre e destile, não há estômago, mas moa, dissolva e ano 15 digira. Aqui não há olhar, mas saudade. Não há silêncio, mas ouça. Aqui

n. 31 não há estrada, mas caminhe. Você não está aqui, mas esteja.

\section{Regra XVII}

Autópsia - Se for autopsiado, não é preciso gritar, basta mover levemente o dedo indicador, ou dar uma única piscada para que todos se assustem. Aceite a cirurgia (Regra XI), mas não a autópsia. Não há nada que possa interessar teu corpo, agora. Não há conhecimento que possam extrair do teu corpo que ainda possa interessar teu corpo - só ao corpo deles, movendo-se no mundo deles, que já não é o teu. Como um rato foge ao experimento científico, fuja à autópsia. Reaja à luz branca em que te cortam. Reaja à assepsia, ao medo de que contamine. Reaja ao interesse científico, às anotações, à falta de nojo e de pudor com que te cortam. Levante os braços. Assombre. Fuja. Reaja.

\section{Regra XVIII}

Manco ou amputado, teu corpo, perdido da graça, é ainda mais profundamente corpo. Cego, surdo, burro, teu corpo, perdido da visão, da audição, da inteligência, teu corpo é ainda mais corpo, agora. E debaixo da terra é corpo. E quando for cinza e poeira será corpo. Mais corpo, mais corpo ainda. Azul, canção, silêncio, rugido, palavra sem significação. Teu corpo é a juba de um leão adormecido. Um brilhante incrustado no dente. A carne incrustada na carne. Espasmo, intestino, sangramento e palavra. Isso tudo é teu corpo agora, maior e mais corpo ainda.

\section{Regra XIX}

Há um corpo na laje onde escreveram o nome do morto. Há um corpo no nome do morto - escrito ou pronunciado. Ninguém se livra desse corpo mínimo ${ }^{6}$. 


\section{Autorização}

Permite que sua imagem seja usada? Permito. Que sua voz seja ouvida? Permite que seus pensamentos se transformem em palavras? Que seu pau entre no corpo dela, dessa aí, permite? Permite que ela solte gemidos estridentes por causa disso? Permite a asma noturna? Que paguem dinheiro por seu trabalho? Permite a coruja? Que toquem tua pele? A água salgada nos olhos? Permito, permito. Permite que a luz inche tua pupila, que a bexiga se esvazie, permite uma expressão de alívio nessa hora, permite? Permite não saber por que, nem quando, nem onde, apenas que, apenas quê? Permite o envelhecimento e que a todos que conhece e admire aconteça exatamente o mesmo? Permite que antigas crianças se transformem nisso? Permito. Nisso aí? Permito. Permite debaixo da terra? Permito. Permite a decomposição? Permito. Permite uma observação? Permito. Permite uma pergunta, uma única pergunta? Permite aqui, permite ali, permite quando? Permite essa merda? Uma esmola? Uma segunda chance? Um cigarro? Uma moeda? Permite que te julguem, dando nota? Permite que nunca? Permite o cachorro ganindo? Permite ouvir dizer, ouvir falar, cuspir na cara, gozar na boca, uma risada? Permito. Tem minha permissão para tudo isso. Que o sábio explique, o poeta metrifique, o cansaço encha o sono? Permite uma rua? Permite a montanha? A ratazana? Permite o lajedo? Essa lua? Permito, permito. Enchendo seu copo com um novo punhado de cubos de gelo, a cara tão sem rugas quanto a careca que nenhum fio de cabelo perturbava, o velho estendeu os braços acenando a seus quadros, ao leito de seu rio, ao veludo de suas poltronas e aos montes escarpados daquela cidade maravilhosa, que também considerava sua. Tinha respondido com propriedade a todas as perguntas e estava satisfeito consigo. Tudo parecia em seu lugar. Seu corpo, dentro do chambre estampado com brasões, como a bandeira de um clube esotérico, estava devidamente aquecido e em prumo, sem nenhum desequilíbrio ou urgência intestinal que o perturbasse. Sentiu com tristeza que adormeceria, antes de gozar mais longamente aqueles momentos de felicidade. Então tocou o sino, chamando a enfermeira, e pediu uma pílula que o despertasse ${ }^{7}$.

7. Ibidem, p. 121-122. 
Há uma camada de poeira que recobre as coisas, protegendo-as de nós. Polvilho escuro da fuligem, fragmento de sal e alga, toneladas de matéria em grãos que vão cruzando o oceano transformam-se em fiapos transparentes depositados pouco a pouco para preservar o que ficou embaixo. Quase nada se tem pensado a respeito deste fenômeno. Trata-se provavelmente de uma enorme operação de camuflagem, de equalização de um sinal remoto que perceberíamos facilmente na ausência desta montanha de pequenos agregados. Algo dentro das coisas está sendo disfarçado, escondido a qualquer preço, e até mesmo o extrato de rocha, terra e lava seca onde pisamos, construímos nossas cabanas e parimos nossos filhos parece estar ali para embrulhar alguma coisa que tende ao centro. A agregação infindável da Gravidade, da massa caindo sobre a massa, matéria abraçando matéria num apetite sempre renovado, constitui a expressão mais evidente deste princípio. É como se um ser primordial, pleno numa gargalhada antiga, percebesse uma fenda em seu corpo ou pus em seus olhos, uma penugem de cor estranha em seu pêlo ou ainda uma má-formação em seus membros. Antes de abismar-se na tristeza, envergonhado com o que percebeu, conseguiu ainda recobrir-se com o que havia à sua volta, apanhando tudo o que deixara escapar de si, pois até há pouco fazia parte de seu corpo perfeito a matéria de que agora se vestiu - a poeira e a terra, a folhagem e a penugem, o fogo explosivo das estrelas e a escuridão congelada. A gigantesca espiral em movimento, concêntrica, como um feto encolhendo-se, com que se retraiu esta divindade incapaz de compreender-se, de incluir-se inteira, ensinou ao tempo e ao espaço, que até então estavam nela, eram ela, o seu comportamento básico — tombo, solavanco, suspensão; areia, matéria, enigma. É difícil compreender como terá irradiado pelas coisas esta atitude de reclusão e de vergonha. A matéria, na verdade, talvez não seja mais do que a expressão primeira desta fuga. Ao invés da afirmação explosiva a partir de um nada pleno, toda a Física teria por princípio a negação e o ocultamento de alguma coisa percebida, o disfarce de um defeito, a espiral protetora em torno a uma identidade cheia de desgosto. A expansão do universo, segundo este ponto de vista, deveria prosseguir apenas até que o recobrimento se cumprisse, tornando-se depois desnecessária. Mas se o fluxo de poeira e lava em nosso planeta continua, se a luz desvia em seu espectro para o vermelho, indicando o afastamento progressivo de estrelas já tão afastadas, é porque o corpo envergonhado não pôde ainda se cobrir inteiro. Na verdade, o movimento com que giram os gases aquecidos, os choques de massas polares 
com o ar mais leve e quente que vem dos trópicos, a condensação das tempestades sobre o oceano, todo o sal lançado na atmosfera, a luta das mucosas e das guelras, o sofrimento mesmo das aspirações humanas, dragões espalhando lantejoulas e escamas, vidas ceifadas, pedaços de madeira que naufragam, olhos que a catarata vela, bacia onde moram os sargaços, tudo o que ficou cinzento e floriu depois na primavera, tudo o que o outono equalizou com prata e monotonia, o rosado leve do poente, o ar que enche o peito de alegria, parecem na verdade parte de uma astúcia, gestos furtivos que não compreendemos, seqüelas de um corpo enorme e defeituoso que tenta inutilmente recobrir-se, sumir debaixo da aparência. $\mathrm{O}$ motivo de seu fracasso, provavelmente, deve-se ao fato de a matéria de que se recobre ser ela mesma parte sua, compartilhando sua decepção - também ela quer ocultar-se, reproduzindo infinitesimalmente o movimento que deveria ser restrito ao caroço que lhe deu origem. Acaba assim traindo por mimetismo e semelhança o papel que lhe foi designado enquanto a longa litania do que existe, virando seu rosto para dentro, neutralizando suas feições, desfila lentamente. Talvez seja uma contradição curiosa aquilo que tanto se esconde precisar de testemunhas como nós, que contemplamos, admiramos e, ainda por cima, achamos bonito. Pois assim todo o apagamento progressivo, a nebulização periódica do que poderia brotar em flores enlouquecidas, a monotonia de uma linguagem que devia ser de carne, uma matemática que devia ser de troncos e de mármore, sim, toda a laguna de possibilidades que a frágil ambição de nossos órgãos não soube verdadeiramente desejar, ganha seu imprimatur, sua documentação enquanto necessidade - abraçamos o que foge de nós, invertemos seu próprio desgosto e recusa, julgamos como perfeita a natureza envergonhada e defeituosa, aderimos, enfim, perdidamente e para sempre ao que parece belo, porque nos conformamos ao amar ${ }^{8}$.
Nuno Ramos

Escritos de artista

8. Idem. 0 pão do corvo. São Paulo: Ed. 34, 2001, p. 09-11. 
Palavras são feitas de matéria escura, quase sólida. Secam rapidamente, depois de pensadas ou ditas. Mas secam também antes que saiam da boca, quando deixamos de usá-las de maneira apropriada. Há duas grandes famílias de palavras - as que são súbitas e as que roubam tempo. As primeiras devem seu nome ao fato de aparecerem pouco, como pontilhões transparentes e de curtíssima duração até aquilo que nos rodeia. Vêm em geral cercadas de espanto por seu misto de precisão e harmonia, como uma enorme coincidência que logo some, carregando consigo a breve duração de sua promessa. De tão raras, parece sempre que estamos diante das palavras súbitas pela primeira vez. Formam, neste sentido, o oposto complementar da segunda família de palavras, conhecidas como rouba-tempo, que estão sempre disponíveis e aparecendo em legião. São estas que nos cercam a cada momento, a tal ponto que já não é possível separar nossa vida da sua. Para quê agem assim, roubando nosso tempo como um roedor nos leva para a sua toca ou um marsupial para a sua bolsa? É uma questão complicada. Parecem apegadas à superfície dissipada da vida, que não consegue fixar-se e encontra nelas o seu coagulante. Estão para as palavras súbitas como os anões de jardim para as pessoas vivas. No entanto, a própria superficialidade de sua existência imperfeita confere uma poderosa característica a esta família: sua reprodutibilidade. Como partículas subatômicas, trombam o tempo numa dança desordenada, mas aparentando grande lógica, de verbos e substantivos que expele sufixos, rimas incompletas, hexâmetros de pés quebrados e um número enorme de frases feitas semicurculares. É esta pasta confusa que obscurece o céu estrelado sobre as nossas cabeças, o astro vermelho que tomba diante de nós ou a branca fatia da lua. Normalmente, em sua forma mais virulenta, as rouba-tempo comentam aquilo que está sendo visto: "parece que posso tocar as estrelas!”, "nunca vi um sol tão vermelho!” ou "a lua está transparente como porcelana”. Naturalizam assim sua própria condição dissipada, atazanando as mentes que dominam. Sim, porque é próprio das rouba-tempo afligir seu hospedeiro impedindo que se distraia, que se una verdadeiramente àquilo que o chama; ficam resmungando baixinho, soletrando nomes e pronomes, embalando o órgão que deveria no entanto utilizar-se delas num sono acordado que vai terminar por matá-lo. Esse órgão, o cérebro, ao invés da emissão de raios amorosos para a qual parece destinado, captando a freqüência da matéria, da memória, dos afetos ou mesmo do que se esconde na sombra mais profunda para reproduzir, como se fosse um sino, sua onda vibratória (que não vem de 
cima, mas do interior das coisas), fundindo-se assim ao pulso único, irreprodutível, de uma maçã, por exemplo, e vibrando de volta com ele, ao invés de seguir essa vocação, possuído pelas rouba-tempo, este cérebro fala, ou pensa que fala - pensa, ou pensa que pensa. Abandona assim a matéria transparente, neutra e vazia da harmonia física e vibratória entre os seres do campo preventivo destes pequenos duplos de som organizado que parecem, no fundo, querer apenas perpetuar-se. Como o ser vibra em ondas, logo assumiram a forma sonora, procurando confundir-se com sua fonte ou, ao menos, manter com ela um parentesco primário, uma matéria comum ondulatória de que o som parece a configuração mais explícita. No entanto, é nesta mesma astúcia que acabam por revelar-se, pois sabemos que não vibra o emaranhado pantanoso de semi-palavras e fragmentos de orações que nos turva a mente o dia todo, parecendo mais um bolo amorfo que expande e colapsa sobre si do que a fuga bailarina, cíclica e sempre renovada de uma palavra súbita ou de outra onda qualquer, luminosa, cheia de sargaços, infravermelha ou afetiva. Parecem ter nessa dificuldade de expansão o seu ponto fraco, o avesso da reprodutibilidade extrema que as caracteriza. É a partir daí que devem ser predadas. Sim, porque se não as alimentarmos com visões ou sentimentos, se não trouxermos o vento até elas, se não dissiparmos a clausura asfixiante de sua falta de objeto, entram rapidamente em colapso. É bem possível que o cérebro hospedeiro colapse junto, ouvindo o ranger das correntes mesmo enquanto dorme, mas desta crise extrema pode também brotar a libertação e o silêncio. A fadiga do cérebro doente, a concentração de todas as suas forças contra o invasor que já o tomou quase completamente, acaba muitas vezes por fazer nascer um órgão renovado, que cedeu à doença partes inteiras de sua matéria e de suas habilidades, mas reuniu ainda assim o essencial para uma sobrevida. Trata-se, na verdade, de uma operação bastante arriscada, mas que obteve sucesso muitas vezes, pois diante da morte do hospedeiro as próprias rouba-tempo recuam, diminuindo o nível de sua atividade. Ao que parece, pressentem o ponto de colapso do organismo, recolhendo-se como um exército ordenado de formigas. O que lhes interessa não é de fato destroçar o hospedeiro mas mantê-lo num estado de torpor em que processa, numa espécie de fotossíntese, a substituição contínua do que lhe é exterior pela sintaxe desordenada das próprias rouba-tempo. Existe ainda uma segunda forma de combatê-las, mais estranha e menos eficaz, mas que diversas vezes apresentou resultados. Consiste em materializá-las, escapando à ilusão aérea e vibratória que as caracteriza. A primeira tarefa deste método é sempre grafar as palavras, evitando a forma oral. Como já dissemos, o caráter imaterial que assumiram,
Nuno Ramos

Escritos de artista 
ARS através de ondas sonoras, é que permite sua camuflagem astuciosa. Esta ano 15 técnica consiste portanto em dar corpo às palavras, tornando-as pesan. 31 das, onduladas, viscosas ou sujas, escrevendo-as com barro, concreto ou metais fundidos, sempre em escala significativa. A primeira propriedade que adquirem neste caso é a lentidão: até que terminemos de construí-las repetiremos mentalmente tantas vezes o som que as caracteriza que este já não terá qualquer sentido. Além disso, como criar sintaxe entre fósseis paralisados, carregados de matéria e de peso; como encontrar a posição de um verbo e de um adjetivo numa situação eminentemente física, feitos de terra, por exemplo, num terreno que a chuva encharcou? Isoladas, presas na matéria, não podem mais trombar indefinidamente umas com as outras nem reproduzir-se. Parecem perder sentido confor9. Ibidem, p. 16-18. me ganham corpo, e então já não há perigo de que nos enganem? 


\author{
Abandono meu baço \\ canta a moto na calçada. \\ Que foi, quem fui \\ que fiz eu do que me deram, $v$ \\ aleu? Questões graves. \\ Mas pronuncio, agora e até o fim \\ o longo sermão da luz meu \\ pâncreas canta - autora \\ confusa, borrando e fumando \\ o fundo e a figura \\ poderias por um só \\ segundo, s \\ egundinho, apagar-te \\ para que eu enxergue melhor o que vai dentro? \\ Lâmpada sem vidro \\ doadora de um forno \\ contágio entre o ilhado, o 1 \\ indo e o inalcançado \\ pior \\ pronome, mas que dentro do incêndio minha córnea \\ entoa um hino estende as antenas a todos os vizinhos \\ - quase enlouqueci fazendo isso \\ sozinho e sem acesso ao manual de instruções.
}

Ando pela areia não é areia, não há areia, deixem quieta

$$
\text { a areia }
$$

não é mulher, não há mulher, deixem quieta, imóvel

sua penugem, pêss

ego, ei, senhor, não é mar, não há mar, deixe quieto o mar

não mergulhe, sermão da lassidão

não leia nada, sermão da quietude

não envelheça, sermão de haver ferrugem

e antes de nós essa folhagem

enraizada no carvão

levando meu caixote embaixo do braço

e falo alto, bem

alto. Ei, siri, ouve agora o meu sermão. 
iri

n. 31

e a tua, senhor

para, não esbarra em meu banquinho inesgotável 1

enga-lenga, mas ouço

também

e grave declaração de bens da natureza

lavrada num cartório pantanoso

no linguajar que tem a lama

quando lambe os móveis - um fluxo

hidráulico, inconsútil

que junta madeira e veludo

formando tudo o que há haja! seja!

debaixo da louça liquida (anis, às vezes).

Vejo daqui um bulbo

por exemplo, uma lâmpada

fumê com raízes subindo.

Quem, senhores, quem

essas raízes procuram - e em que $\mathrm{s}$

entido? Não sei exatamente o que perguntam

essas vozes quase minerais

mas seu que as transfiro

fisicamente, sim

(aproxime-se de mim, senhor

toque em mim agora, seria mesmo

melhor me lambe

r como um pirulito)

sei que transfiro essas perguntas

aos ouvidos de lagartos

largados ao sol

- meu estimado público.

Venha, meg

era, já

era

a senhora não paga nada

e não precisa ter medo

da seminudez

de um semicadáver

completamente vivido. 
São essas as vozes que regem meus sermões.

Ouço ali, na hora agá

Escritos de artista

como um rato que encontrou seu queijo

sujeito e predicado em cópula perfeita.

Canto então, caniço frágil

perturbando a impassível face.

Eis a multidão

disposta sobre a areia. Ali está.

Brincam com seus baldinhos

formando uma arena.

Querem bronze, sal, ventura.

Eis-me aqui, sozinho e c

ontraposto, minha voz ensaiando seu desgosto.

Nobre senhor, aguente esta pergunta

que

quer

dizer

agora?

Começo pelo á, depois o gê, depois o ó, depois o erre e

o á de novo.

Aguentem também, senhores

minha resposta

- agora não quer dizer nada

é apenas um troféu

de latão, o nome

do campeão gravado.

Ouço a voz do gado af

ogado, desconhecido, sem forma ou sentido.

Aponto o dedo ao besouro súbito (já s

umiu

em seu acúmulo diário).

Ouço a voz dos cães, cada miado

soletrado lentamente, para que eu entenda.

Seria a voz da natureza

e é assim que a recebo, grato.

E entendo. Entendo, sim. Entendo perfeitamente.

Tem a gravidade pretérita das estrelas

a profundidade sofrida das estrias

um peso de areia tombando na ampulheta.

Então pergunto ao que sumiu — há canal 
ainda ou já secou teu rio

ano 15

e os bichos, agora

n. 31

onde banhavam-se, espargindo

alegria, apenas afundam?

Por mais que enumere

a crista aguda de cada galo

cantor incrustado em gestos

e passos, sei que agora não quer dizer nada.

É simples assim,

Cuidado, senhores

com meu frágil banquinho, ún

ico arrimo que guardo neste mundo.

Melhor não duvidar

agora que me têm à sua frente

à mercê das doces palavras

que escutam perfeitamente.

Agora que sabemos, todos já sabemos: não quer dizer

$$
\text { nada. }
$$

Escuto vozes. Ouçam as vozes que escuto. São essas vozes aí.

E desço do banquinho ${ }^{10}$. 
